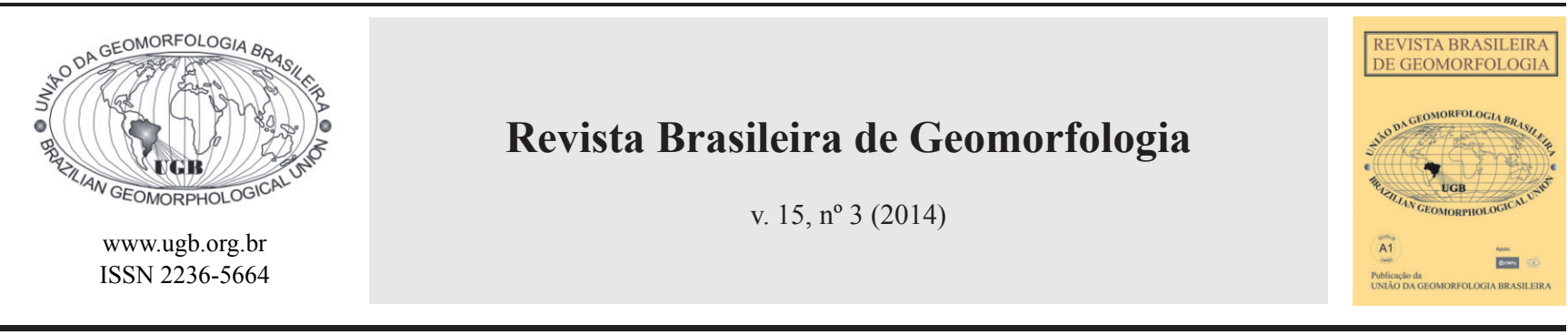

\title{
ANÁLISE DAS FEIÇÕES CÁRSTICAS DESENVOLVIDAS NO MACIÇO DAS AGULHAS NEGRAS - RIO DE JANEIRO
}

\section{ANALYSIS OF THE KARSTIC FORMS PRESENT AROUND THE SUMMIT OF AGULHAS NEGRAS - RIO DE JANEIRO}

\author{
Helbert Luiz Coutinho Talim
}

Departamento de Geografia, Centro Universitário de Belo Horizonte. Av. Prof. Mário Werneck, 1685, Estoril, Belo Horizonte/MG, Cep: 30455-610, Brasil.

E-mail: helbertgeo@yahoo.com.br

Guilherme Taitson Bueno

Programa de Pós-Graduação em Geografia, Pontifícia Universidade Católica de Minas Gerais. Av. Itaú, 505, Dom Cabral, Belo Horizonte/MG, Cep: 30535-012, Brasil

E-mail: gtaitson@ig.com.br

\section{Informações sobre o Artigo}

Data de Recebimento:

01/05/2012

Data de Aprovação:

$30 / 06 / 2014$

\section{Palavras-chave:}

Kamenitza, caneluras, intemperismo químico, quartzo sienito, feições cársticas, Agulhas Negras.

Keywords:

Karstic forms, chemical weathering processes, syenite quartz, Agulhas Negras.

\section{Resumo:}

O Maciço do Itatiaia é conhecido como parte integrante da unidade morfoestrutural do Cinturão Orogênico do Atlântico, na região Sudeste do Brasil. Inserido nesta unidade geomorfológica, o Maciço das Agulhas Negras apresenta-se na paisagem de forma imponente, com vertentes íngremes e com um grande número de pequenos canais verticais, subparalelos, que dão nome ao pico. Para alguns autores, a glaciação quaternária foi o fator preponderante para a elaboração dessas formas. Outros pesquisadores, entretanto, propõem que essas formas seriam de natureza cárstica. Nos últimos anos, estudos sobre feições cársticas em rochas não carbonáticas estão sendo desenvolvidos na América do Sul e na Europa, principalmente sobre os arenitos, quartzitos e também sobre rochas as alcalinas. As pesquisas geomorfológicas e geológicas em rochas não carbonáticas consideram que estas são resultado dos processos de intemperismo químico, físico-químico e biológico. Nesse contexto, é possível inserir as feições cársticas presentes no quartzo sienito, no grupo de rochas silicáticas. O objetivo do estudo é caracterizar e descrever, qualitativamente, as feições presentes no entorno das Agulhas Negras, tais como: kamenitzas, lapiás e caneluras; foi realizado um levantamento bibliográfico sobre o tema, além do registro fotográfico. Os resultados encontrados mostram que as formas identificadas no maciço são verdadeiras feições cársticas, e foram registrados diversos estágios de desenvolvimento destas. As observações apontam para uma origem principalmente baseada no processo de dissolução química. 


\section{Abstract:}

The Itatiaia's quartz-syenite massif is known as an element of the morphstructural unit of the Atlantic Orogenic Belt, in the Southeast of Brazil. As a part of this geomorphological unit, the summit of Agulhas Negras imposes itself at the landscape, with its steep slopes and many small vertical and sub-parallel cannelures, which give the summit its name. For some researchers the quaternary glaciations were the major factor for the appearance of these forms. Others, however, propose that they could have a karstic nature. In the past few years, studies on karstic forms over non-carbonate rocks are being developed in South America and in Europe, especially over sandstones and quartzites, and also over basic rocks. The geological and geomorphological researches on non-carbonate rocks consider that these are the result of chemical, physicochemical and biological weathering processes. In this context, it's possible to include the forms on the quartz-syenite into the group of karstic features on silicated rocks. This paper aims to characterize and describe, qualitatively, the forms present around the Agulhas Negras, such as: kamenitza, lapiaz and cannelures. A bibliographic research and also a photographic record have been made. The results show that these forms are true karstic ones, registered in different stages of development. The observations indicate an origin mainly based on the chemical dissolution process.

\section{Introdução}

As paisagens do território nacional sempre despertaram o interesse de pesquisadores em relação às feições cársticas sobre as rochas carbonáticas e não carbonáticas. Essas formas foram esculpidas através dos processos de intemperismo químico, físico-químico ou, ainda, biológico, sobre as distintas unidades morfoestruturais, compostas por rochas metamórficas, sedimentares e ígneas, proporcionando uma diversidade de feições. No entanto, a maior ocorrência de feições cársticas se dá, sobretudo, em áreas de bacias sedimentares, nas quais os calcários e os arenitos são mais suscetíveis à ação da água (BIGARELLA et al. ,1994; PILÓ, 2000; etc.).

Estudos atuais têm mostrado que essas feições cársticas ocorrem também nas regiões dos escudos cristalinos, nos quais se encontram os granitóides (BLANCANEAUX, 1977; dentre outros). O processo de intemperismo é semelhante ao das outras rochas, contudo os tipos de feições apresentam-se de formas diferentes devido à composição química das rochas ígneas. Essas paisagens se formaram devido à ação do clima, o que favoreceu o processo de intemperismo ocorrido sobre a litologia do maciço. Segundo Casseti (2005), o clima se caracteriza como elemento morfogenético sobre as vertentes.

A discussão que envolve a semelhança em relação à morfologia superficial de feições cársticas sobre as rochas não carbonáticas em comparação com as feições em rochas carbonáticas, vem crescendo ao longo dos anos na literatura científica. Cabe destacar os estudos realizados por Blancaneaux (1977); Bigarella et al. (1994); Rodet et al. (2009); Hardt et al. (2009), dentre outros, sobre a formação das feições cársticas desenvolvidas através do processo de dissolução, sobretudo nos quartzitos e arenitos. Esse reconhecimento vem sendo aceito também por estudiosos especialistas em relevo cárstico.

Um exemplo deste tipo de feição pode ser encontrado no Maciço do Itatiaia, mais especificamente sobre as vertentes das Agulhas Negras. O maciço encontra-se na divisa dos estados de Minas Gerais e do Rio de Janeiro, e está inserido no Escudo Atlântico Brasileiro. O Maciço das Agulhas Negras está compreendido no planalto da Serra do Itatiaia, sendo considerado o terceiro ponto mais elevado da região sudeste $(2.791,55$ m) segundo Teixeira e Linsker (2007). O quartzo sienito que modela as escarpas das Agulhas Negras é responsável pela beleza cênica na região da Serra da Mantiqueira.

Como objetivo geral deste trabalho, propõe-se discutir os prováveis processos de intemperismo que originaram as feições cársticas situadas no Maciço do Itatiaia, mais precisamente na vertente das Agulhas Negras, e classificá-las, tendo por base dados primários obtidos através de levantamento de campo e secundários, tais como produção bibliográfica, mapas e registros fotográficos. A classificação das categorias de feições da área estudada (rochas não carbonáticas) será feita ao tomar-se como referência os conceitos e as definições utilizados para as feições cársticas formadas em rochas carbonáticas. Além disso, pretende-se descrever as categorias de feições encontradas sobre o quartzo sienito, rocha predominante nas Agulhas Negras.

Os autores Penalva (1967), Modenesi-Gauttieri (1992) e Clapperton (1993), citados por Modenesi- 
-Gauttieri (1998), iniciaram seus estudos com o objetivo de encontrar registros de marcas de ação glacial nos blocos e matacões depositados por todos os setores das vertentes do maciço das Agulhas Negras, provenientes, supostamente, do período de glaciação ocorrida no Quaternário. Outros estudos foram desenvolvidos anteriormente sobre os matacões depositados no sopé do maciço, e estes foram interpretados por Ebert (1960, apud MODENESI-GAUTTIERI, 1998, p. 21) como sedimentos glaciais originados na penúltima glaciação. Em relação às formas presentes sobre as vertentes, Modenesi-Gauttieri (1998) descreve que a morfologia tem sido comparada com as feições presentes em áreas de climas frios. Apesar dos inúmeros esforços dos autores citados, ainda não foi possível afirmar que as feições encontradas na região se deram através do processo de glaciação.

Contrário à linha de pesquisa dos autores mencionados acima, em 1955, Odman apresenta argumentos contrários ao processo de glaciação pleistocênica na região, ao observar feições interpretadas como de natureza cárstica, do tipo caneluras e kamenitzas, nas partes mais elevadas do Maciço do Itatiaia, que compreende as Agulhas Negras (RIBEIRO FILHO, 1963).

Através dos dados levantados pelos autores Bigarella, et al. (1994), Leinz (1998), dentre outros, é possível sugerir que a dissolução química seja um dos principais responsáveis pelas feições presentes nas vertentes das Agulhas Negras, o que reafirma a linha de pesquisa de Odman.

\section{Metodologia}

Os estudos seguiram uma abordagem do ponto de vista qualitativo, e foram elaborados em duas etapas: campo e gabinete.

Em campo, percorreu-se o trecho selecionado para o estudo, partindo da base da vertente até o seu cume denominado Pico das Agulhas Negras. (Figura 1). Neste lugar, foi observada a presença de feições semelhantes às desenvolvidas em rochas solúveis. As observações procuraram reconhecer os diferentes tipos de feições e seus estágios de desenvolvimento, em busca de elementos que sustentassem a hipótese de uma origem cárstica para essas rochas. Em seguida, foi feito um registro fotográfico, através do qual procurou-se registrar as diferentes feições presentes na área de pesquisa. As feições foram registradas em escala macro e micro.
No primeiro caso, buscou-se inseri-las no contexto do maciço; enquanto, no segundo caso, buscou-se registrar detalhes de sua morfologia.

Em gabinete, foi desenvolvido o levantamento bibliográfico referente ao tema contemplando livros, revistas, dissertações, teses e mapas do IBGE e do Projeto Sul Minas. Foram consultados autores tais como: Ribeiro Filho (1963), Bigarella et al.(1994), P. Blancaneaux (1977), Modenesi-Guattieri \& Nunes (1998), L. Piló (2000), G. Sgarbi (2007) Hardt et al. (2009) e Rodet et al.(2009). Além disso, analisou-se a topografia da área, através da folha Agulhas Negras / SF-23-Z-A-1-4 na escala 1:50.000 (IBGE, 1988), para se conhecer a morfologia das vertentes. Do ponto de vista geológico, foi utilizada a folha Pouso Alto / SF-23-Z-A-I na escala 1:100.000 (PROJETO SUL MINAS, 2003), para melhor entendimento das unidades geológicas presentes no maciço do Itatiaia.

\section{Aspectos naturais das Agulhas Negras}

A área em estudo está inserida nas coordenadas UTM Fuso 23 K (E: 534867,682 / N: 7525051,737), na região sudeste do Brasil, mais especificamente, a oeste do Rio de Janeiro, sendo que a maior parte da área de exposição está situada nos municípios de Itatiaia e Resende. No estado de Minas Gerais, encontra-se na região sul, inserido no município de Bocaina de Minas Gerais. O acesso ao local pode ser feito partindo de Itamonte, por um trecho de $20 \mathrm{~km}$ da BR 354 sentido Itamonte / Engenheiro Passos, 16,5 km da BR 458 até o local conhecido como Abrigo Rebouças, chegando à base das Agulhas Negras (Figura 1).

A geologia presente na área de estudo, de acordo com Teixeira (1961, apud MODENESI-GUATTIERI e TOLEDO, 1993, p. 46), encontra-se na faixa de intrusão alcalina de arranjo semicircular conhecido como ring dike. Após a intrusão deu-se a formação do conjunto de rochas alcalinas. Nas áreas de cimeira do maciço do Itatiaia a litologia é composta por quartzos sienitos datados, segundo Trouw et. al. (2000), pelo método K-Ar, em $66 \mathrm{Ma}$, (Terciário). De acordo com Sgarbi (2007), o quartzo sienito é constituído essencialmente por feldspatos alcalinos com pequena concentração de quartzo. Para Ribeiro Filho e Penalva (1967 apud TROUW et. al., 2000, p. 419), os quartzos sienitos são rochas "plutônicas félsicas, equigranulares, médias a grossas, compostas por ortoclásio e quartzo e quantida- 

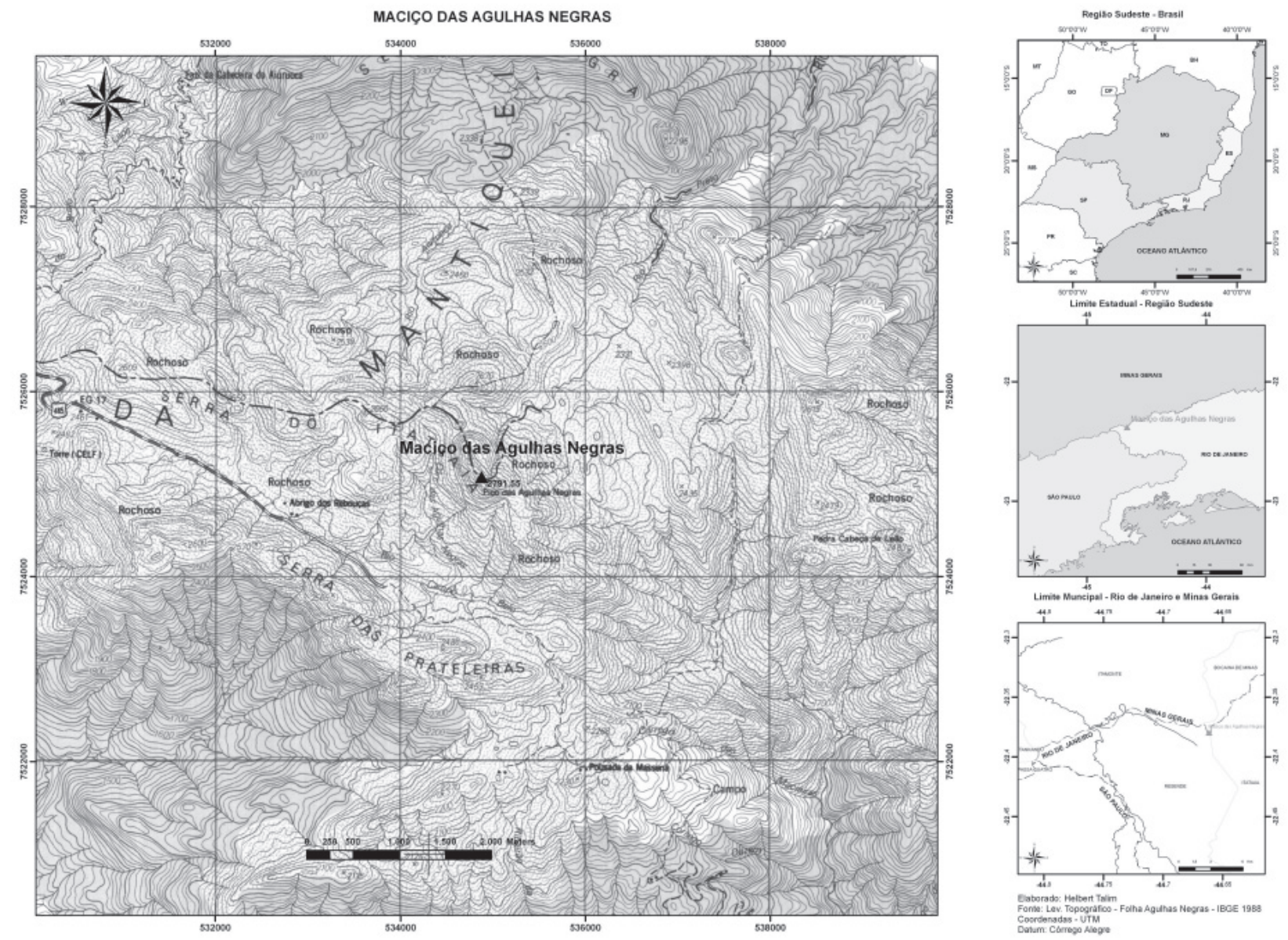

Figura 1 - Mapa topográfico do maciço (1988, adaptado do IBGE, segundo TEIXEIRA e LINSKER, 2007).

des subordinadas de piroxênio, anfibólio, plagioclásio, biotita, titanita, apatita e magnetita". Por ser uma rocha ígnea, contém uma porcentagem de sílica. Na constituição mineralógica dos quartzo sienitos, predominam os feldspatos acalinos e destaca-se a alta porcentagem de sílica (entre $66 \%$ e $52 \%$ ), sendo, por isso, considerados como rochas intermediárias, segundo a classificação de rochas ígneas proposta Sgarbi (2007).

A Serra do Itatiaia encontra-se sobre o domínio morfoestrutural do Cinturão Orogênico do Atlântico, soerguido durante o Cretáceo e início de Terciário (SILVA et al., 2001). Essa formação surgiu em decorrência da reativação Sul-Atlantiana, evento de movimentação tectônica advindo da abertura do Atlântico Sul. A unidade morfoescultural é denominada de Maciços Alcalinos Intrusos, cuja formação originou-se devido à associação de magmatismo alcalino e à abertura do Atlântico Sul (ALMEIDA, 1992, apud SILVA et al., 2001, p. 6).
A geomorfologia do Maciço do Itatiaia apresenta altitude superior a $1.300 \mathrm{~m}$, com áreas escarpadas, o que proporciona vertentes com gradiente de elevado a muito elevado, formas retilíneas a côncavas, com predominância de depósitos de tálus e colúvios na base.

A morfologia do conjunto das Agulhas Negras é constituída por topo em forma aguçada, atingindo valor hipsométrico de $2.791,55 \mathrm{~m}$. Suas escarpas são constituídas por quartzo sienitos, com diversas linhas de fraturas que atingem um desnível de aproximadamente $500 \mathrm{~m}$ (Figura 1). Nas áreas escarpadas, é possível observar a formação de caneluras. O regime climático predominante na região possui características particulares, devido à altitude e por estar localizado sobre os trópicos úmidos, na margem oriental do continente sul-americano. Além disso, está sob domínio do sistema tropical atlântico e também do sistema polar, de acordo com Modenesi-Guattieri \& Nunes (1998). 


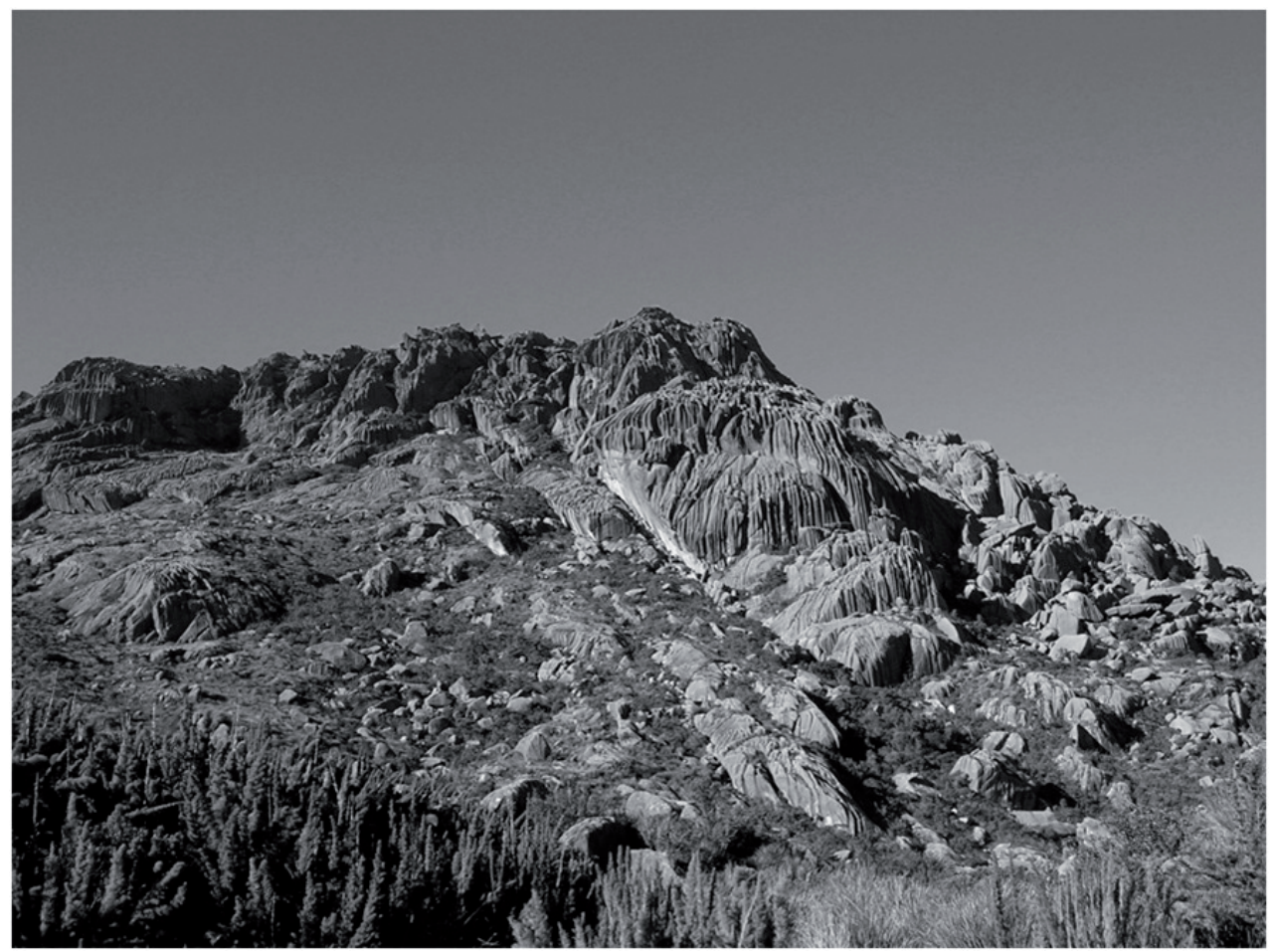

Figura 2 - Caneluras desenvolvidas no quartzo sienito entre as partes altas, médias e baixas da vertente das Agulhas, originadas através do processo de intemperismo químico.

O clima nas áreas mais elevadas do Maciço do Itatiaia, de acordo com o IBDF (1982), encontra-se estabelecido pelos padrões de Köppen, sob o domínio do clima mesotérmico, com verões brandos e chuvosos e com inverno seco. O índice pluviométrico varia entre $1.967 \mathrm{~mm}$ e $2.400 \mathrm{~mm}$. As chuvas ocorrem durante o verão entre os meses de dezembro e fevereiro e são mais intensas em janeiro. O período de estiagem ocorre durante os meses de abril e agosto. Os dias são mais quentes durante o mês de janeiro e mais frios durante o mês de julho. A máxima no verão pode atingir $21,4^{\circ} \mathrm{C}$, durante o mês de fevereiro. As geadas ocorrem na região durante todo período de inverno, e há, nos meses de breves geadas, uma alta frequência de granizo. Neste período, a temperatura pode chegar aos $-15^{\circ} \mathrm{C}$ (IBDF, 1982).

De acordo com o IBDF (1982), a tipologia vegetal predominante nas áreas mais elevadas das cimeiras do Itatiaia é constituída pelos campos de altitude. Suas vertentes são compostas por mata baixa e têm como predomínio herbáceas e briófitas. Essa vegetação tem como principal característica a capacidade de suportar temperaturas muito baixas. Segundo Richter (2004), as espécies encontradas nas vertentes do maciço apresentam estruturas adaptadas a essas condições, com densa pilosidade e folhas coriáceas. Cabe destacar as principais espécies desta fisionomia: capim-de-anta, bambuzinho, bromélias e orquídeas (nomes populares). Além disso, ressalta-se a presença de espécies de líquens e algas distribuídas sobre a rocha na vertente.

\section{Princípios da ação do intemperismo sobre as rochas}

Entende-se como intemperismo:

Um conjunto de modificações de ordem física (desagregação) e química (decomposição) que as rochas sofrem ao aflorar na superfície. Tais processos intempéricos atuam através dos mecanismos modificados das propriedades fisicas dos minerais e rochas (morfologia, resistência, textura e etc.), e de suas composições químicas (composição química e estrutural cristalina). Posterior a esse afloramento na superficie seus minerais entram em desequilibrio através de uma serie de reações químicas (TEIXEIRA et. al., 2003, p.141). 
Além dos fenômenos físico e químico citados acima, fenômenos biológicos têm influência direta nos processos intempéricos (LEINZ e AMARAL, 1998). Todos esses fenômenos podem atuar isoladamente ou em conjunto.

\subsection{Intemperismo físico e químico}

As rochas são compostas por diversos tipos de minerais, os quais estão presentes em diferentes proporções. A partir do momento em que as rochas recebem grande incidência de calor durante o dia e resfriam durante a noite, elas, com o passar dos séculos, tendem a sofrer mudanças, tanto internas, quanto externas. Essas mudanças são conhecidas como decomposição física.

Além da temperatura, a água é outro agente que modifica as características da rocha. Trata-se, nesse caso, de decomposição química, a qual pode se dar por meio de dissolução, hidratação, hidrólise, carbonatação, oxidação e redução (BIGARELLA et al., 1994). No caso das rochas ígneas, os mais importantes deles são a dissolução e a hidrólise.

Certos minerais estão sujeitos à dissolução, que consiste na solubilização completa. Nesse caso, se enquadram os principais minerais que compõem os calcários. Entretanto, via de regra, os quartzos em condições normais são muito pouco solúveis. Geralmente, $o$ aumento da temperatura contribui para a maior solubilidade dos minerais (BIGARELLAet. al., 1994). A reação química que ocorre entre os minerais em conjunto com a água é conhecida como hidrólise. Neste caso, as rochas que possuem silicatos na sua composição mineralógica sofrem ataques químicos da água (LEINZ, 1998).

Ressalta-se que as rochas ricas em planos de clivagem, xistosidades e em fendilhamentos, em diferentes escalas (micro e macroscópica), bem como as possuidoras de densas redes de diaclasamentos tendem a apresentar uma intensificação das reações químicas causadas pelo intemperismo.

\subsection{Ação dos organismos no processo de intemperismo sobre as rochas}

Os organismos vivos têm um papel importante no processo de intemperismo sobre as rochas do ponto vista químico. De acordo com Sgarbi, esse processo:

Envolve a ação de componentes químicos relacionados com as atividades orgânicas dos vegetais, assim como a remoção mecânica de materiais granulares de um para o outro na superficie. Os fatores envolvidos no intemperismo biológico são: quelação, ação de cunha de raizes, ação de escavação de animais e corrosão por ácidos vegetais (SGARBI, 2007, p. 313).

Diversos microorganismos são capazes de se adaptar sobre as rochas nuas em condições extremas de escassez de nutrientes, ou seja, são capazes de se desenvolver com uma baixa reserva de alimento. Trata-se de bactérias, fungos, algas inferiores, liquens e musgos.

Segundo Bigarella et al. (1994), os liquens são organismos resistentes e capazes de viver em qualquer tipo de ambiente, como sobre as rochas expostas. Esses seres sobrevivem nas superfícies com pequena concentração de água e extraem os nutrientes dos minerais das rochas através de troca catiônica.

A contribuição dos líquens no processo de intemperismo químico e físico sobre as rochas se dá em conjunto com o processo de expansão das mesmas, nos períodos úmidos, e contração, nos períodos secos. Nesta interface, ocorre a formação do plano de clivagem que ocasiona a fragmentação dos minerais sobre a rocha.

\section{Formação das feições cársticas sobre as rochas não carbonáticas}

A discussão que envolve a semelhança em relação à morfologia superficial de feições cársticas sobre as rochas não carbonáticas, em comparação com rochas carbonáticas, e seus processos de formação, vem crescendo ao longo dos anos na literatura científica. Cabe destacar os estudos realizados por Blancaneaux (1977); Bigarella et al. (1994); Rodet et al. (2009), dentre outros, sobre a formação das feições cársticas desenvolvidas através do processo de dissolução, sobretudo nos quartzitos e arenitos. Esse reconhecimento vem sendo aceito também por estudiosos especialistas em relevo cárstico.

Piló (2000), ao publicar uma revisão bibliográfica sobre "Geomorfologia Cárstica", escreve sobre a tendência da inserção dos quartzitos e arenitos no grupo de rochas carstisfícáveis. Tal proposição, também, foi levantada por Gillieson (1996, apud PILÓ, 2000, p. 89), que considera que a sílica presente sobre as rochas silicatadas tem um papel importante na formação das feições superficiais e sub-superficiais, semelhantes às 
presentes no relevo carste.

No final do século XX e início do século XXI, vários estudos foram publicados a respeito de formas definidas como feições cársticas sobre o grupo de rochas silicáticas, pois os processos envolvendo a gênese dessas formas estariam ligados ao processo de dissolução (BLANCANEAUX, 1977; RODET, 2009; HARDT, 2009; dentre outros). Uma característica marcante é a presença de caneluras que compõem a morfologia nas áreas de rochas silicáticas estudadas até o presente momento. Nesse aspecto, cabe destacar a publicação de Blancaneaux (1977), que descreve o desenvolvimento das caneluras devido à ação do processo de intemperismo químico, físico-químico e biológico sobre o granito Rapakivi, na Venezuela.

\section{Feições cársticas sobre o quarzto sienito}

A discussão que envolve a gênese das formas presentes nas vertentes das Agulhas Negras reforça a possibilidade de uma nova perspectiva ao interpretar as feições cársticas. Esta afirmativa pode ser sustentada ao considerar-se o fato de que toda rocha, independente de sua composição mineralógica, pode sofrer dissolução, levando em consideração o tipo de ambiente em que ela se encontra (HARDT et al., 2009). Além disso, não é possível deixar de lado a possibilidade de que tais fei- ções tenham se desenvolvido devido aos processos de intemperismo químico, físico-químico e biológico sobre os feldspatos alcalinos, minerais estes predominantes no quartzo sienito.

Outros fatores podem ter levado à formação dessas feições cársticas sobre as vertentes das Agulhas Negras. É o caso das chuvas que são intensas durante o verão e ocasionam a ação do processo de intemperismo químico sobre o quartzo sienito, dando origem à formação de pequenos sulcos e estabelecendo os sistemas de drenagem sobre as vertentes escarpadas. De acordo com Leinz (1998), na região do Maciço do Itatiaia, é possível afirmar que os quartzos sienitos sofrem ataques químicos provenientes das águas auxiliados pela ação dos ácidos húmicos provenientes dos liquens.

Ao percorrer a vertente em direção ao ponto culminante das Agulhas Negras, é possível observar três tipos de feições cársticas: kamenitzas, caneluras e lapiás, em diferentes estágios de desenvolvimento sobre os afloramentos.

As kamenitzas encontram-se majoritariamente em grandes quantidades sobre a média e a alta vertentes do maciço. Trata-se de pequenas e médias depressões em formas circulares, ovóides ou elípticas, pouco inclinadas, com $10 \mathrm{~cm}$ a $150 \mathrm{~cm}$ de diâmetro com o fundo plano, presentes sobre as superfícies horizontais (Figuras 3 e 4 ) e verticais do quartzo sienito.

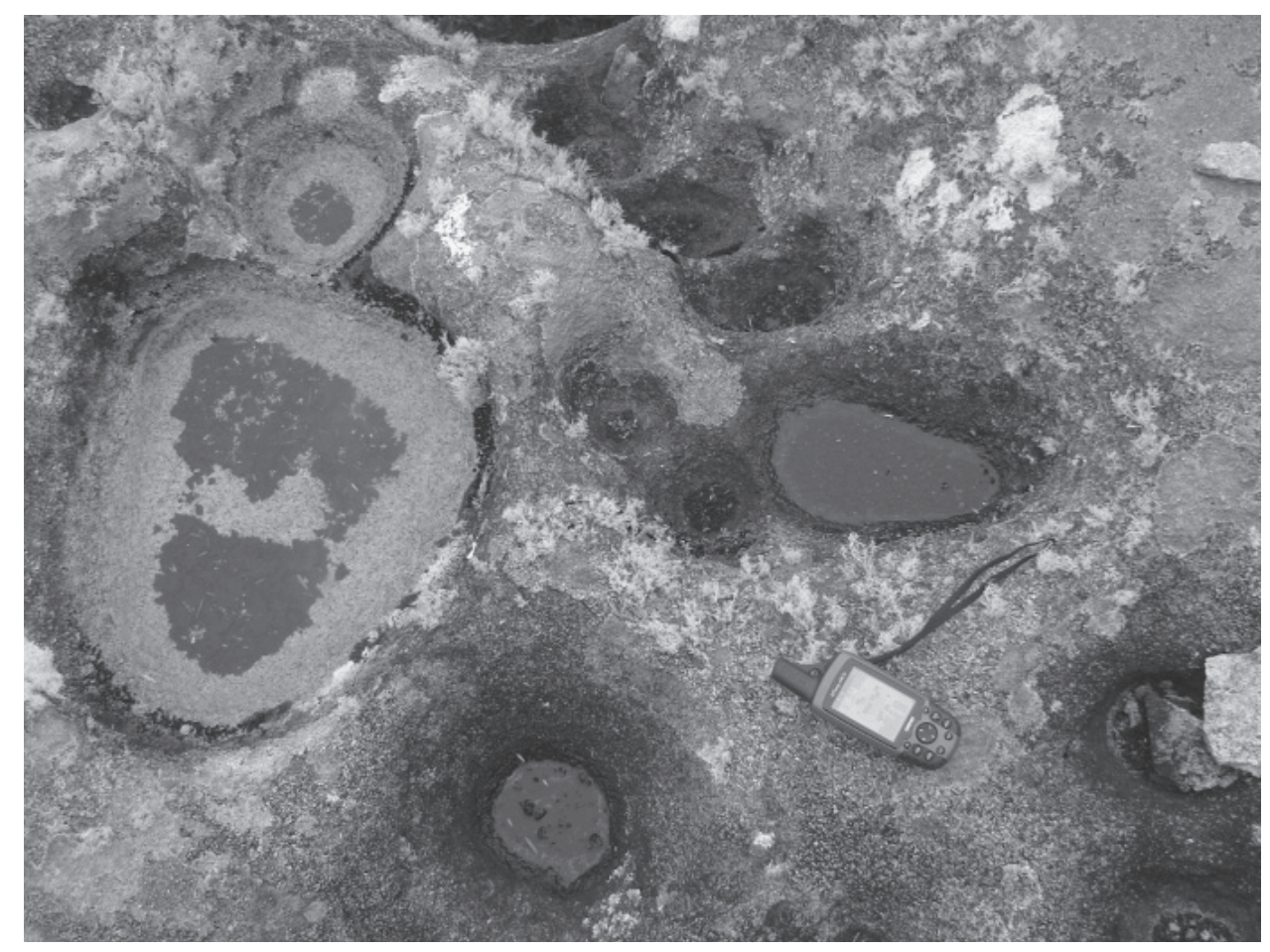

Figura 3 - Kamenitzas presentes sobre as vertentes do maciço das Agulhas Negras. 


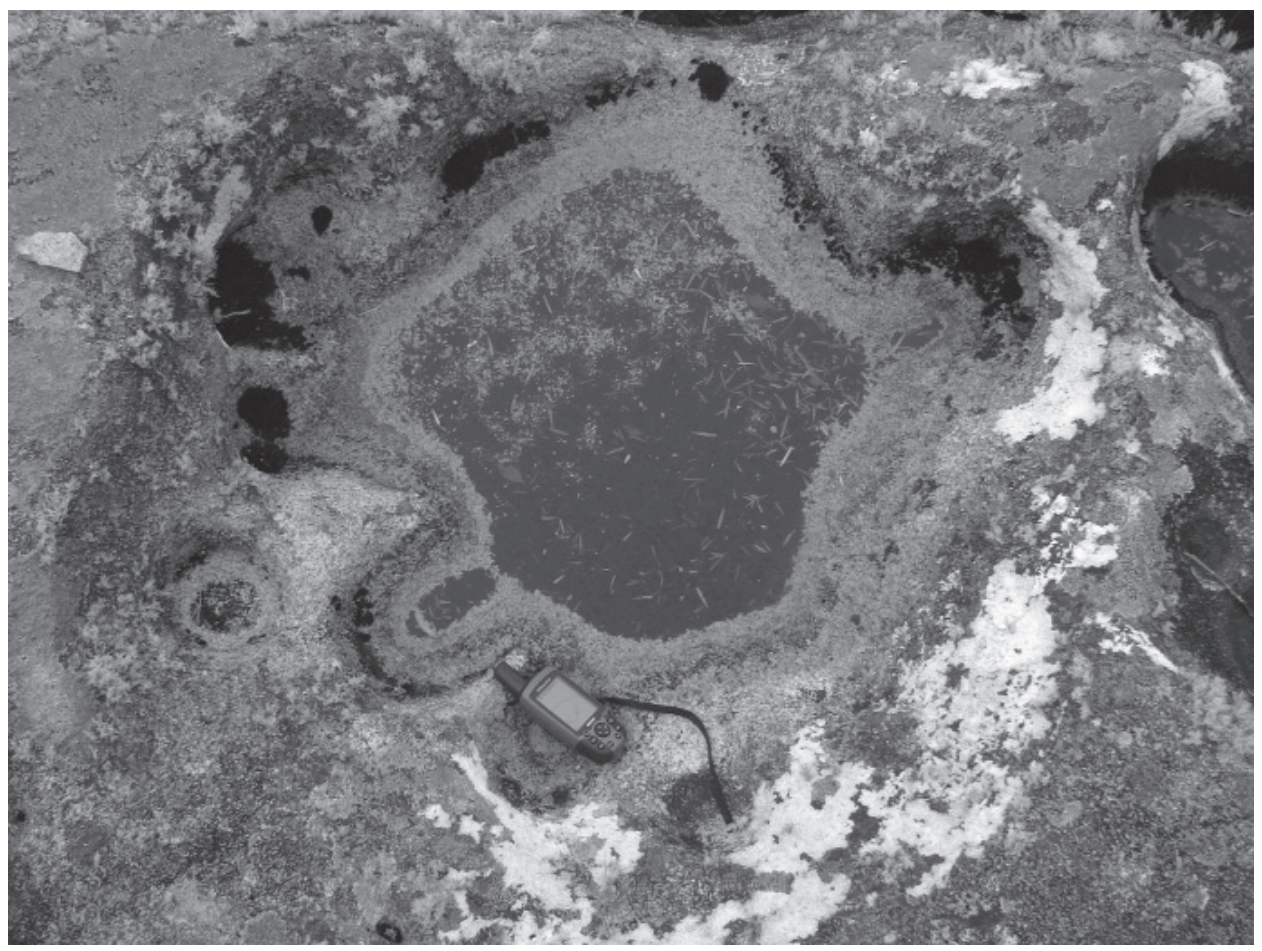

Figura 4 - Ação conjunta da água e agentes biológicos favorecendo a evolução das kamenitzas no quartzo sienito.

As kamenitzas identificadas ao longo das fraturas nos setores de maior declividade da vertente apresentam formas elípticas de pequena expansão, porém com fundos simétricos e muito profundos. Suas bordas atingem de 4 a $20 \mathrm{~cm}$ de diâmetro, com 5 a $18 \mathrm{~cm}$ de profundidade (Figuras 5 e 6 ).
Essas feições se desenvolveram de forma lenta e gradativa (TEIXEIRA e LINSKER, 2007), principalmente sobre as fraturas da rocha exposta ao intenso processo de intemperismo químico. O desenvolvimento das kamenitzas também está relacionado ao intemperismo biológico através do registro de pequenas camadas

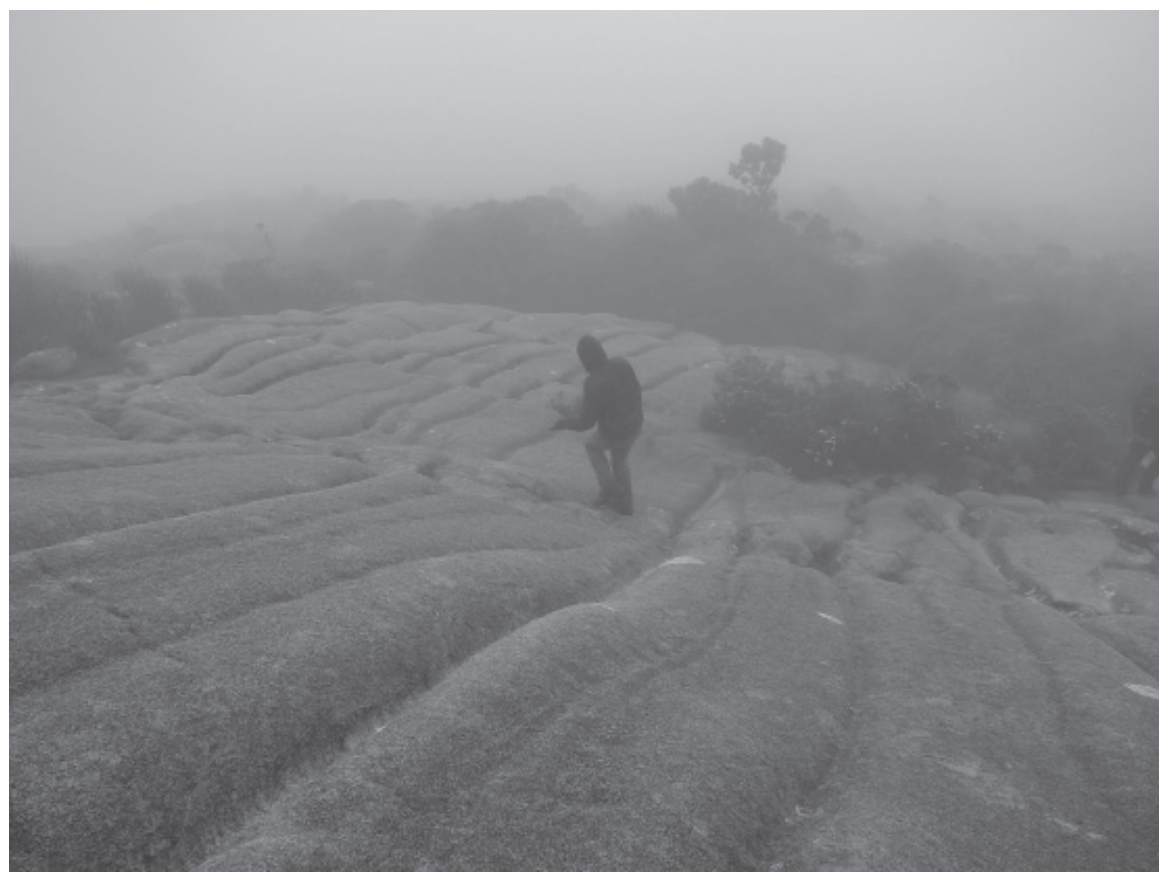

Figura 5 - Visão macro das kamenitzas desenvolvidas sobre as linhas de fraturas do quartzo sienito na área de declividade do maciço. 


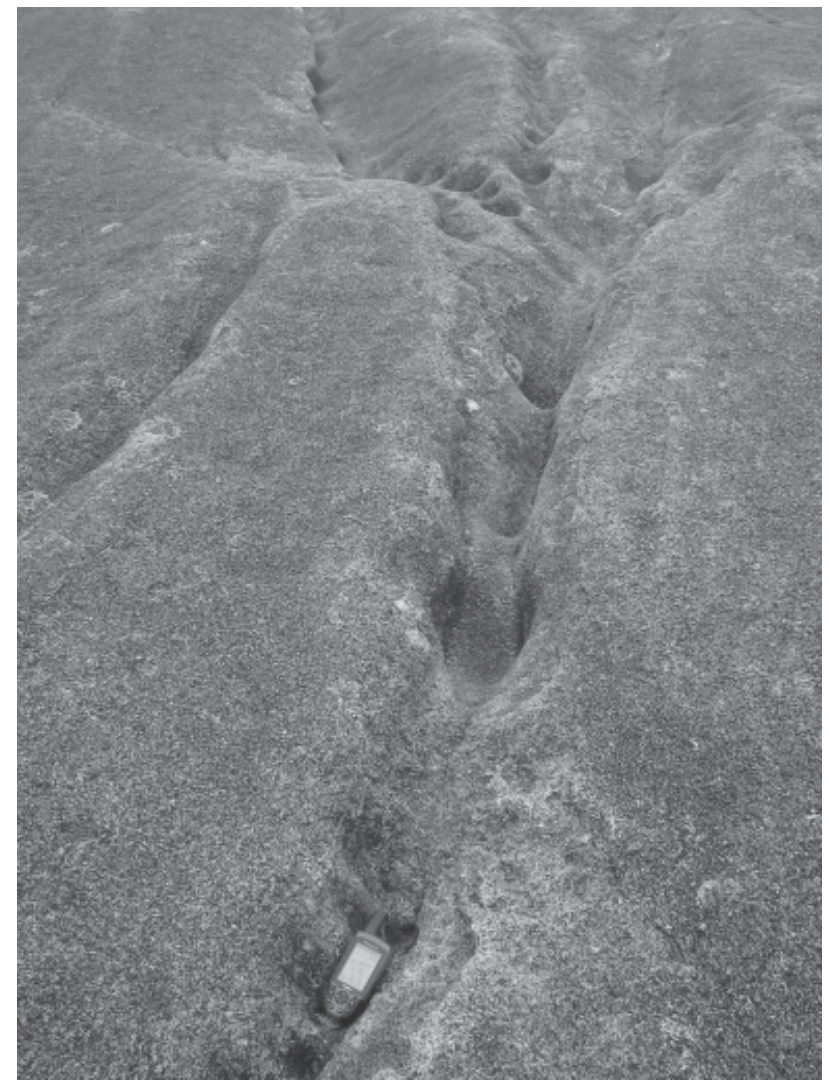

Figura 6 - Detalhe das Kamenitzas na formação de caneluras.

enegrecidas de algas mortas. Pequenas comunidades de liquens nas bordas, além de pequenos seixos de quartzo sienitos intemperizados no fundo, conforme pode ser visto nas figuras 3 e 4 . A ação mútua desses elementos sobre o quartzo sienito nos leva a interpretar que a origem dessas feições está relacionada aos processos de intemperismo químico-físico e biológico.

Outra forma muito comum do relevo carste, encontrada no Maciço das Agulhas Negras, são as caneluras (Figura 7). As caneluras correspondem à formação de sulcos e regos de corrosão de dissolução que se formam sobre o quartzo sienito das vertentes, por onde escoam as águas (BIGARELLA et al., 1994). É importante reconhecer que as caneluras estão diretamente associadas às kamenitzas e às linhas de fraturas predominantes no quartzo sienito.

O papel das kamenitzas na formação das caneluras pode ser explicado a partir da ocorrência dessas feições sobre as superfícies de menor declividade da rocha nas bordas das escarpas que, ao sofrer o ataque químico dos microorganismos em conjunto com a ação corrosiva das águas empoçadas, acarretam o rompimento de uma das bordas das kamenitzas, favorecendo o escoamento superficial da água pelas escarpas do maciço (Figuras 6 e 8). Nesse exemplo, onde as caneluras se encontram sobre as áreas escarpadas, a evolução se dá de forma gradual. Em alguns setores do maciço, foi possível identificar blocos de rochas com caneluras muito evoluídas e foi possível registrar sulcos de corrosão atingindo de 2 a $10 \mathrm{~cm}$ de profundidades na rocha.

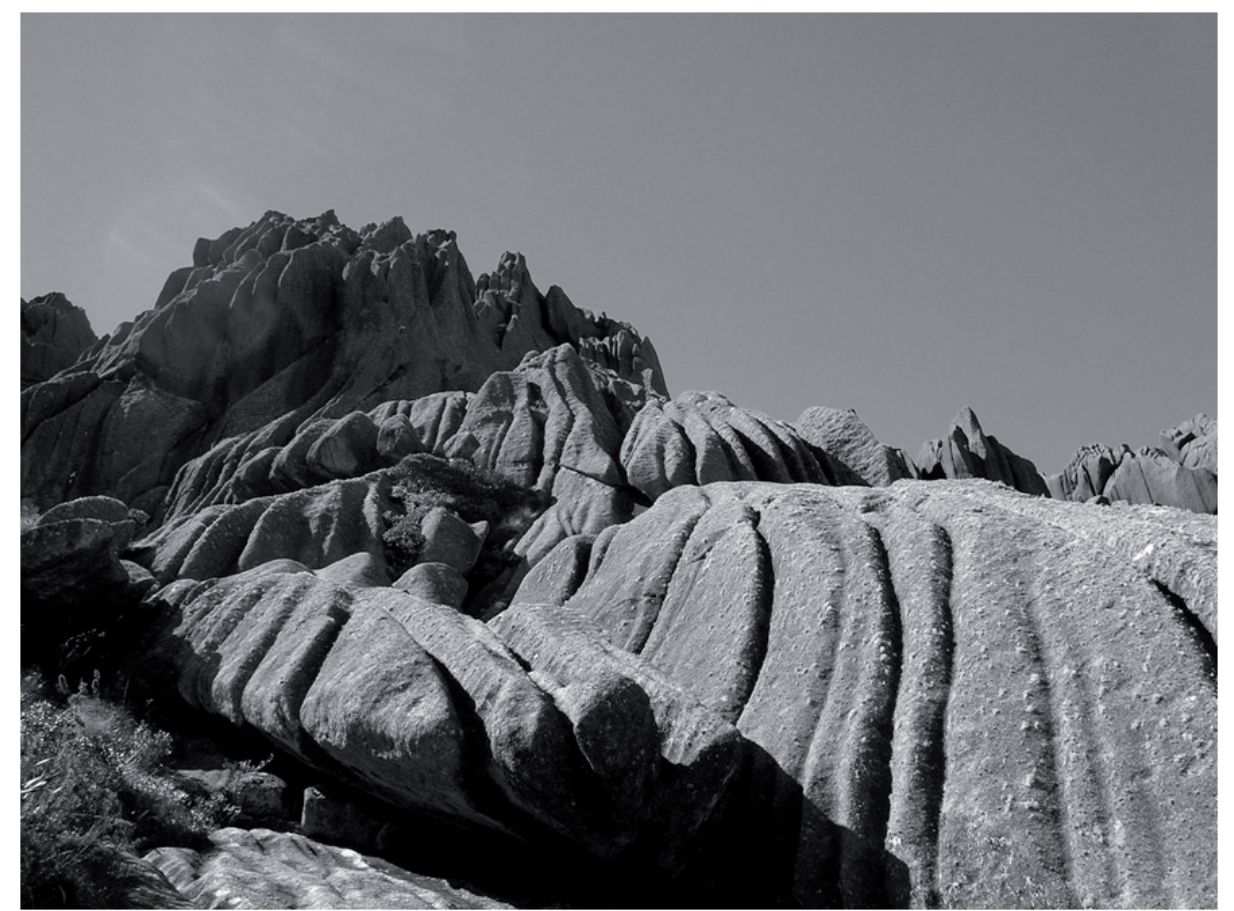

Figura 7 - Registro de sulcos resultantes da corrosão ao longo das vertentes das Agulhas Negras. 


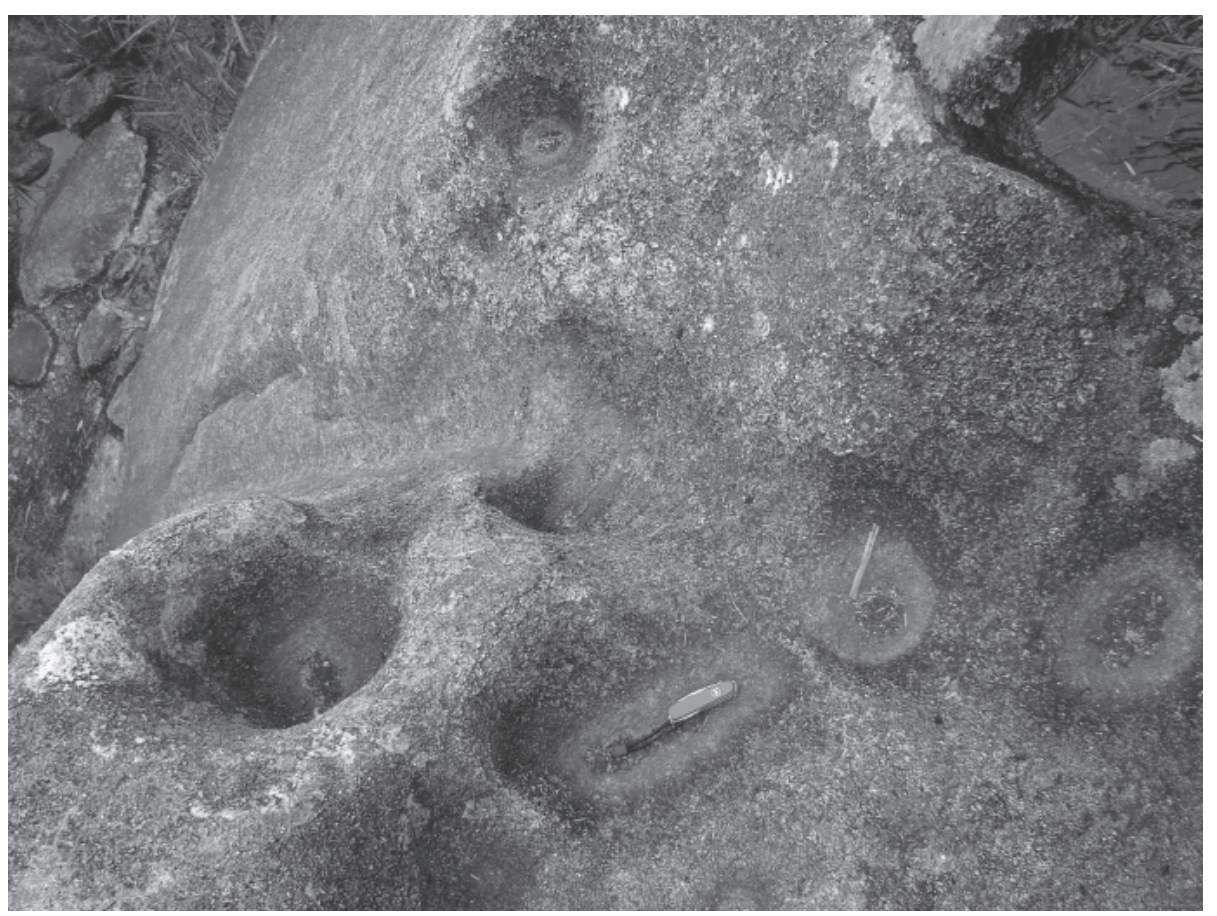

Figura 8 - Rompimento da borda de uma kamenitza favorecendo o desenvolvimento de sulcos erosivos sobre o quartzo sienito dando origem ás caneluras.

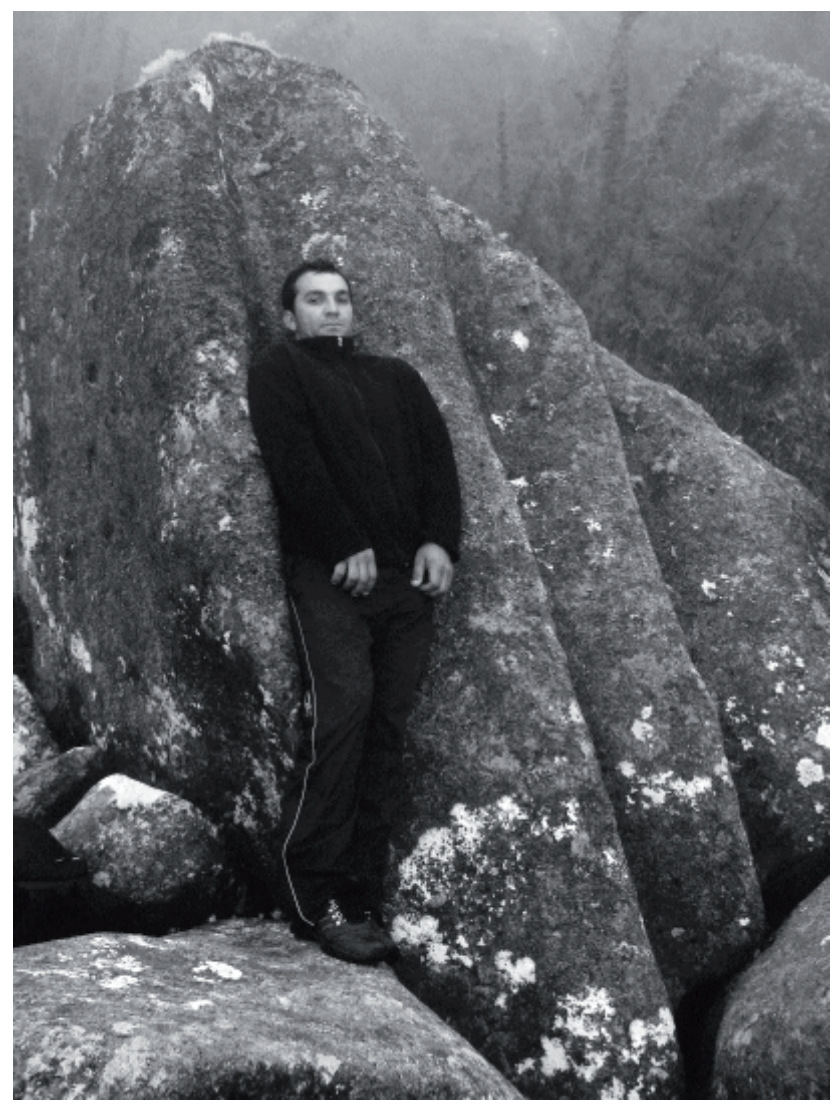

Figura 9 - Detalhe para a dimensão das caneluras que se desenvolveram no bloco do quartzo sienito na média vertente do maciço.
Formas análogas aos conhecidos lapiás formados sobre as rochas calcárias podem ser observadas na media e na alta vertentes do Maciço das Agulhas Negras. A semelhança com os lapiás que afloram nas regiões cársticas pode ser vista claramente na figura 10.

A evolução dos cones cársticos no cume das Agulhas está associada principalmente aos processos de intemperismo químico e físico que atuam sobre o quartzo sienito responsáveis pela formação de kamenitzas e caneluras. As microformas estão diretamente associadas ao escoamento superficial, que favorece a evolução das linhas de fraturas preponderantes sobre os lapiás. As pontas dos lapiás são preenchidas por pequenos conjuntos de kamenitzas que, por sua vez, sofrem ataques químicos e físicos e têm parte de suas bordas rompidas, o que favorece a formação de sulcos e regos ao longo das áreas fraturadas nas escarpas.

\section{Considerações finais}

Os estudos apontam que as feições cársticas identificadas na região das Agulhas Negras de fato foram originadas em conjunto pelos processos de intemperismo químico, físico-químico e biológico sobre os minerais que compõem o quartzo sienito. 


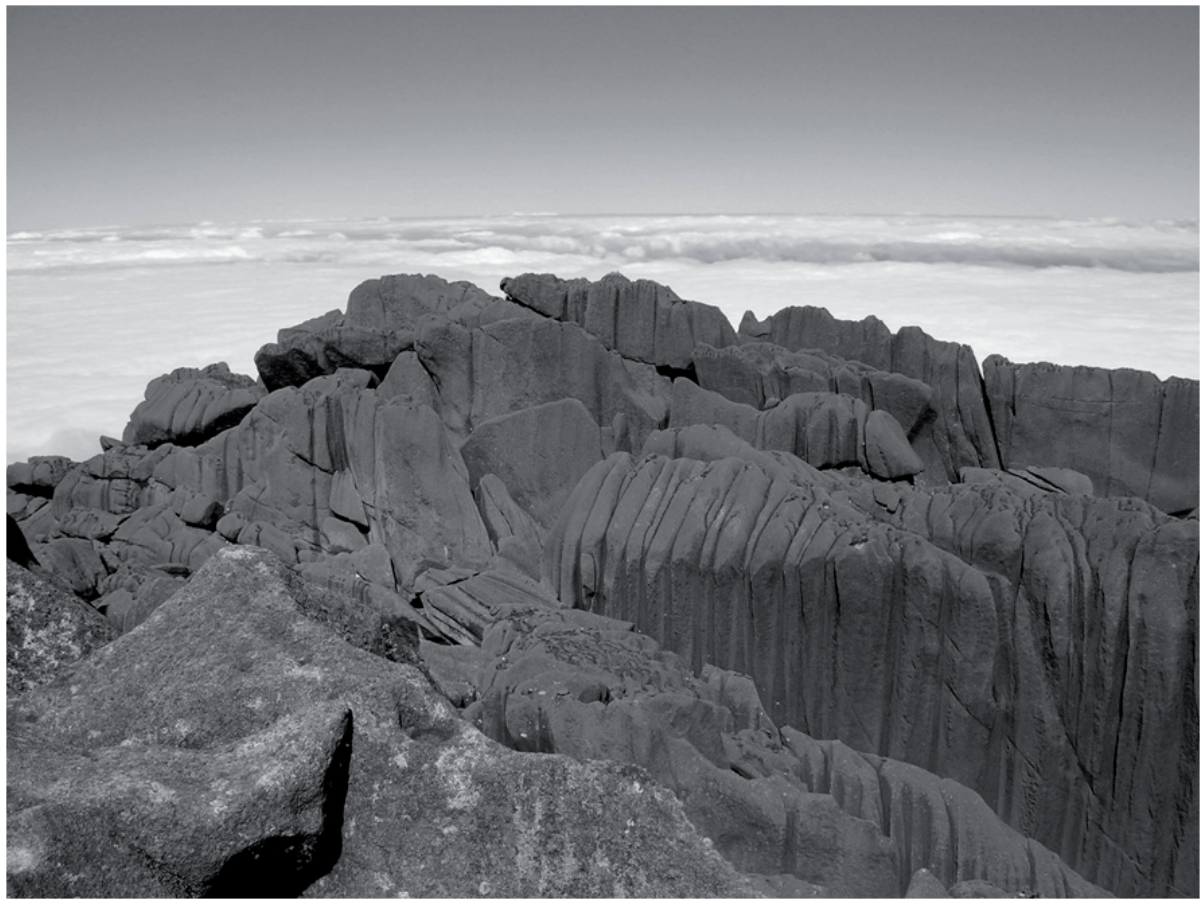

Figura 10 - Vista parcial dos lapiás em diversas direções, na alta vertente do Maciço das Agulhas Negras.

Cabe ressaltar o papel da água na evolução das feições atuando como principal agente de intemperismo químico sobre as linhas de fraturas da rocha, na média e na alta vertentes do Maciço das Agulhas Negras.

Ficou evidente durante o levantamento que as linhas de fraturas presentes sobre as rochas do maciço contribuem para o surgimento e evolução das caneluras. Consideramos que as caneluras estão diretamente associadas à evolução das kamenitzas e dos lapiás no quartzo sienito.

Os estudos indicam que a definição de carste transpõe as rochas carbonáticas conforme já aceito para o quartzito e também para o arenito por diversos autores. É possível afirmar que breve as rochas alcalinas deverão receber maior atenção por parte dos pesquisadores que estudam feições resultantes de processos de dissolução em ambientes de rochas não carbonáticas.

\section{Referências bibliográficas}

BIGARELLA, J. J.; Estrutura e origem das paisagens tropicais e subtropicais: Vol.1 Fundamentos geológicogeográficos, Alteração química e física das rochas, relevo cárstico e dômico. Florianópolis: UFSC, 1994. 425 p.

BLANCANEAUX, P.; Formes d'altération pseudokarstiques em relation avec la géomorphologie des granites précambriens du type Rapakivi dans le territoire fédéral de l'Amazone, Venézuéla. Ch. ORSTOM, ser. Pédot., vol XV, $\mathrm{n}^{\circ}$ 2, Venezuela, 1977. 131-142 p.

CASSETI, V.; Geomorfologia. Goiás: UFG, 2005. 211 p.

FRANÇA, J. L. VASCONCELlOS, A. C.; Manual para normalização de publicações técno-científicas. $8^{\mathrm{a}}$ ed. Revista. Belo Horizonte: Editora UFMG, 2009. 258 p. (Aprender).

HARDT, R.; Exemplos Brasileiros de Carste em Arenito: Chapada dos Guimarães (MT) e Serra de Itaqueri (SP). Campinas. SBE Espeleo Tema. V. 20, n (1/2), 2009 p. 7-23 ISSN 2176-1892.

IBGE. Carta Topográfica - Folha SF.23-Z-A-I-4 MI-2712/4Agulhas Negras. Belo Horizonte: IBGE, 1988. 1 mapa 83X $68 \mathrm{~cm}$, color. 1: 50.000. Mapa com a localização geográfica, contexto geotectônico e estratigrafia da folha de Pouso Alto projetada dentro do Projeto Sul de Minas. Esse levantamento foi realizado através da parceria da UFRJ - UFMG - COMIG - GOVERNO DO ESTADO DE MINAS GERAIS

INSTITUTO BRASILEIRO DE DESENVOLVIMENTO FLORESTAL - IBDF. Plano de Manejo do Parque Nacional do Itatiaia. Brasília, 1982. 207 p

LEINZ, V.; AMARAL, S. E.; Geologia Geral. 13. ed. São Paulo: Nacional, 1998. 399 p.

MODENESI-GAUTTIERI, M. C.; TOLEDO, M. C. M.; 
Morfogênese quaternária e intemperismo: colúvios do Planalto do Itatiaia. São Paulo. Revista do Instituto Geológico. V. 19, n 1, 1993 p. 45-53 ISSN 2176-1892.

MODENESI-GAUTTIERI, M. C.; NUNES, L. H.; Processos geocriogênicos quaternários nas cimeiras da Mantiqueira, com considerações climáticas. São Paulo. Revista do Instituto Geológico. V. 19, n (1/2), 1998 p. 19-30 ISSN 2176-1892.

PILÓ, L. B.; Revisão de Literatura: Geomorfologia Cárstica. Belo Horizonte Revista Brasileira de Geomorfologia. V.1, n.1 2000 .ISSN 88-102.

RICHTER, M.; Geotecnologias no Suporte ao Planejamento e Gestão de Unidades de Conservação. Estudo de Caso: Parque Nacional do Itatiaia 2004- p 162.

RIBEIRO FILHO, E.; Maciços Alcalinos de Itatiaia e de Passa Quatro (Sudeste do Brazil): Contribuição à Geologia e Petrologia. Faculdade de Filosofia, Ciências e Letras da Universidade de São Paulo. Tese de doutorado. 1963, 196p.

RODET, J.; Géoarchéologie du Parc Naturel IEF du Rio Preto. Saint-Martin-aux-Buneaux: CNEK, 2009. 57 p.
SGARBI, G. N. C. (Org.); Petrografia macroscópica das rochas ígneas, sedimentares e metamórficas. 1. ed. Belo Horizonte: UFMG, 2007. 559 p.

SILVA, L. C.; Geomorfológica. In: SILVA, L.C., CUNHA, H.C.S (orgs.) Geologia do Estado do Rio de Janeiro: texto explicativo do mapa geológico do Estado do Rio de Janeiro. Brasília: CPRM. $2^{\text {a }}$ edição revista, 2001.

TEIXEIRA, W. (Org.).; Decifrando a Terra: 2. ed. São Paulo: Oficina de Textos, 2003. 557 p.

TEIXEIRA, W e LINSKER, R. (Coord.).; Itatiaia: Sentinela Das Alturas. São Paulo: Ed. Terra Virgem, 2007. 119 p.

TROUW , R. A. J.; Mapa Geológico - Folha SF.23-Z-A-I Pouso Alto. Projeto Sul de Minas - Etapa 1: Belo Horizonte: COMIG, 2003. 1 mapa 83X $68 \mathrm{~cm}$, color. 1: 100.000. Mapa com a localização geográfica, contexto geotectônico e estratigrafia da folha de Pouso Alto projetada dentro do Projeto Sul de Minas. Esse levantamento foi realizado através da parceria da UFRJ - UFMG - COMIG - GOVERNO DO ESTADO DE MINAS GERAIS 